\title{
Hypotonia-speech impairment-severe cognitive delay syndrome
}

INSERM

\section{Source}

INSERM. (1999). Orphanet: an online rare disease and orphan drug data base. Hypotoniaspeech impairment-severe cognitive delay syndrome. ORPHA:371364

Hypotonia-speech impairment-severe cognitive delay syndrome is a rare, genetic neurodegenerative disorder characterized by severe, persistent hypotonia (presenting at birth or in early infancy), severe global developmental delay (with poor or absent speech, difficulty or inability to roll, sit or walk), profound intellectual disability, and failure to thrive. Additional manifestations include microcephaly, progressive peripheral spasticity, bilateral strabismus and nystagmus, constipation, and variable dysmorphic facial features (including plagiocephaly, broad forehead, small nose, low-set ears, micrognathia and open mouth with tented upper lip). 